\title{
Adult Day Programs in the New Reality of High Prevalence of Dementia-with A Toronto Case Study
}

\author{
Weizhen Dong
}

\section{ABSTRACT}

Objectives: Adult Day Programs (ADPs) have been playing an important role providing services to community dwelling elders and their families in health-related prevention, intervention, and family caregiver support. At the time when there is a high prevalence of dementia among older elders, demand for such services will grow. Learn the experiences of ADPs can help identifying service gaps, which are crucial for developing measures to improve such programs' effectiveness.

Methods: This is a case study on the ADPs at the Toronto Geriatric Centre with qualitative research strategy. Interviews and focus group discussions were the data collection methods employed to gather feedbacks from its staff members, clients, and family caregivers.

Results: The ADPs at the TGC are helpful to their clients and their families, but have issues in language accessibility, physical accessibility (programs' schedule and transportation), financial accessibility (affordability), and care accessibility-there is a lack of professional caregivers for those participants who need onsite care.

Discussion: The high prevalence of dementia among ADPs' clients and the resource shortage are the main difficulties facing the TGC. If it was to achieve its intended goal, more resources are needed for their improvements in accessibility, which would involve a user-friendly operation schedule, free or minor-cost transportation, and sufficient program staffing that include professional caregivers. Covid-19 pandemic poses challenges to the entire eldercare sector. ADPs' post-pandemic arrangements should address emerging needs of the elders they serve. Community elders, especially those persons with dementia, and their families need ADPs for aging at home.

Keywords: Adult day programs (ADPs), Canada, dementia; family caregiver, persons with dementia (PWD).

\section{INTRODUCTION}

Aging is a global challenge today and dementia is a high prevalent illness among older adults. Canada's rapid population aging is associated with the increase of dementia prevalence rate in recent years. There are about half a million Canadians living with dementia and one in five in Canada have had experience caring for PWD. How to provide needed support and services for persons with dementia (PWD) are crucial to the wellbeing of the patients and their families. Adult Day Programs (ADPs) were created to help community dwelling elders with various needs. They usually include dementia specific programs for supporting services for PWD and their family caregivers. Although dementia is believed to be non-curable and irreversible, ADPs are seen as helpful for PWD and their families.

This study explores the ADPs' helpfulness to their clients and families, and their accessibility at the Toronto Geriatric Centre (TGC). The ADPs staff members at the TGC and caregivers of the PWD provided their insights on the issues surrounding the services of ADPs. The findings of this research will provide ADPs for their future improvement, and most importantly, inform relevant government departments how they can support the healthy development of ADPs in the post-pandemic society.

\section{Methodology}

This study employed a qualitative research strategy. Through this strategy, detailed information concerning ADPs were collected from the participants, which pieced together at least the partial reality of the ADPs at the TGC.

\section{A. Study Setting}

Toronto Geriatric Centre (TGC, coded name), which provides eldercare services include long term care, community education services, and various ADPs. This setting was selected because it has outstanding reputation in the community.

\section{B. Participants}

Family caregivers to PWD and ADPs staff members. 


\section{Participants' Recruitment Method}

The TGC initial contact for this project distributed an announcement introduced this project's objectives and called for volunteers to participate. Based on the researcher's fieldwork schedule, available staff members and family caregivers to PWD were recruited for the study. A staff volunteer also assisted to schedule interview and focus group discussions.

\section{Data Collection Methods}

1) Face-to-face interview ( $\mathrm{N}=20 ; 1-2$ hours); and

2) Focus group discussions (6 groups, $\mathrm{N}=56 ; 2$ hours).

\section{E. Research Questions}

1) As an intervention strategy, is the ADPs a helpful resource for people with dementia and their respective families? Has the program realized its intended goals? And

2) How accessible and affordable are the ADPs? Are there ways in which such programs could provide more effective service for PWD and their family caregivers? If so, what are they?

\section{BACKGROUND}

\section{A. Aging and Dementia in Canada}

17.5 percent Canadians are aged 65 and over, and baby boomers account for the majority of seniors [1]. The aging trend will continue, and the aging group's proportion to the Canadian national population is expected to grow in the coming years and decades. The 2016 census counted 5.9 million seniors, compared with 5.8 million children who were 14 or under. Statistics Canada's population projection shows the gap between the two age groups will widen (Fig. 1). By 2031, almost one-in-four Canadians would be senior citizens, while the share of children would remain at 16 per cent [2].

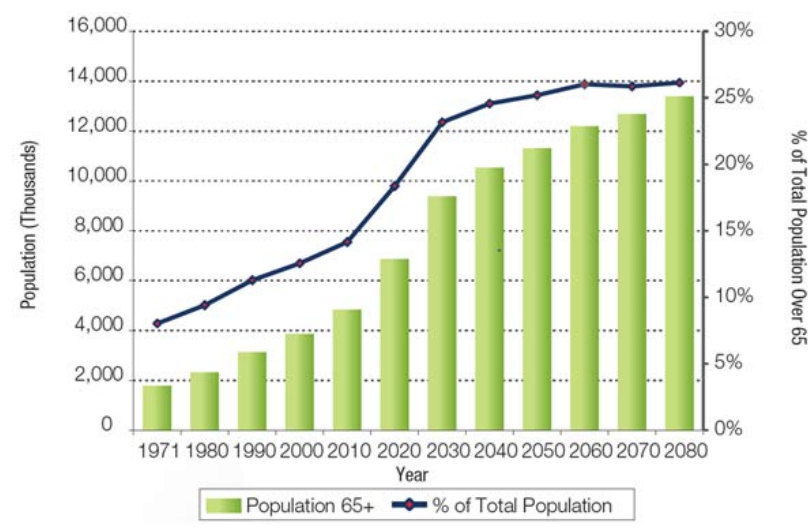

Fig. 1. Population 65 Years and Over, Canada. Statistics Canada (19712010) and Office of the Superintendent of Financial Institutions (20202080) [3].

High prevalence of dementia among elders is one of the great challenges in an aging society. There are half a million Canadians living with dementia, with about 25,000 new diagnoses each year. The number of cases is projected to reach 937,000 by 2031 [4]. Dementia is a collection of syndromes characterized by a plethora of cognitive, emotional, and behavioral impairments [5]. The combined cost for providing care to those living with dementia is a total of $\$ 10.4$ billion annually, from both Canadian healthcare system and out-of-pocket expenditures [6].

Dementia is particularly prevalent among older adults. It consists of neurological disorders that cause a progressive decline in cognitive function, which include Parkinson's disease, Huntington's disease, Alzheimer's disease, Lewy bodies dementia, or vascular conditions [7], [8]. The onset of dementia may be associated with head trauma, overconsumption of alcohol, genetic predispositions [9]. Early symptoms of dementia include language and memory deficits, general confusion, trouble with depth perception, and changes in one's mood and personality [10].

According to Statistics Canada, dementia is a high-cost health issue. Per capita care cost of its hospitalization and long-term care are particularly high compared to no neurological diseases. Specifically, high hospitalization cost for younger age groups and high long-term care cost for older age groups (Fig. 2).

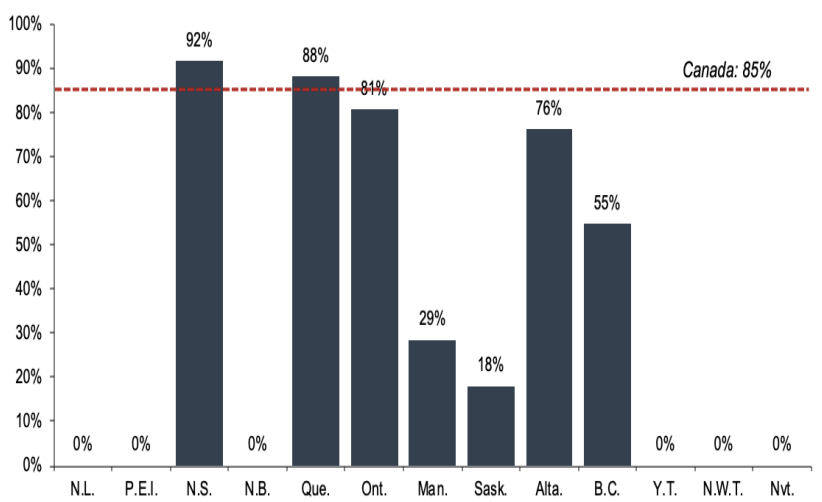

Fig. 2. Deaths from residents in long-term care and retirement homes as a proportion of the total number of deaths in each province or territory (as of June 1, 2020) [11].

\section{B. Family Caregivers' Challenges in Caring for PWD}

In 2018, about one in four Canadians provided unpaid care to a family member or a friend with long term health condition [1]. A study states that formal care in average was 79.6 hours per month, while informal care was 259.6 hours a month in average, which is three times that of the formal care. Therefore, caregivers influence the quality and quantity of dementia care.

TABLE I: PERSONS WITH DEMENTIA AT HOME RECEIVE HOME

\begin{tabular}{ccc}
\multicolumn{3}{c}{ CARE [12] } \\
\hline Categories & Young onset & Seniors \\
\hline \hline Severe cognitive impairment & $27 \%$ & $20 \%$ \\
Depression & $35 \%$ & $25 \%$ \\
Medical instability & $69 \%$ & $76 \%$ \\
Care provided by children & $18 \%$ & $58 \%$ \\
Care provided by spouse & $44 \%$ & $32 \%$ \\
Care provided by others & $38 \%$ & $10 \%$ \\
Average unpaid caregiver hours & $31 \mathrm{hrs}$ & $26 \mathrm{hrs}$ \\
per week & & \\
\hline \hline
\end{tabular}

PWD need high level of care. With limited formal care access, family informal care became the only solution for many families. This means the PWD's daily assistance are provided by one or more persons of their family and relatives. Table I shows PWD's home care burden in the year 20152016 in Canada. It shows adult children were the main caregivers for their parents (58\%), and spouses were the main 
caregivers for the young onset PWD (44\%). Unpaid caregivers of PWD spend an average of 26 hours a week on caregiving, compared with 17 hours for caregivers of other seniors. Unpaid caregivers of PWD also face higher levels of distress than those caring for other seniors: "almost twice as many caregivers of seniors with dementia exhibit symptoms of distress, such as anger, depression or feeling unable to continue (45\% versus $26 \%)$." [13].

TABLE II: KEY FACTORS OF CAREGIVING IN CANADA [14]

$28 \%$ of Canadians (or 8.1 million) report having provided care to a

family member or friend with a long-term health condition, disability or aging need in the past year.

Three-quarters of family caregivers (or 6.1 million) were employed at the time, accounting for $35 \%$ of all employed Canadians.

$44 \%$ of employed caregivers report having missed an average 8 to 9 days of work in the past 12 months because of their caregiving responsibilities.

$36 \%$ of young caregivers arrived to work late, left early or took time off due to their caregiving responsibilities.

$\$ 5.5$ billion annually in loss of productivity due to caregiving-related absenteeism.

Each year Canada loses the equivalent of nearly 558,000 full-time employees from the workforce due to the inability to manage the conflicting demands of paid work and caregiving.

2.5 million caregivers report that they try to balance caregiving with paid employment.

$46 \%$ of aged $15+$ have provided care to a loved one.

$57 \%$ of informal caregivers are women.

$40 \%$ of caregivers experienced depression.

$44 \%$ of them are between 45 to 64 years old and in the prime of their careers.

$30 \%$ caregivers for elders took time off work $450 \mathrm{hrs} /$ year, or about $8.5 \mathrm{hrs} /$ week.

By 2046, informal caregivers will contribute over 2.6 billion hours of unpaid work.

The challenge Canadians face in providing care to their family members is real. Nearly a half of Canadians aged 15 and older, more than eight million, have provided care to a loved one; and $44 \%$ of them are mid-aged and in the prime of their careers (Table II). Working age family caregivers' caregiving burden is affecting the national economy because they have to take time off from work or retire early [15].

\section{Adult Day Programs (ADPs)}

The ADPs services are integral to dementia care in the community as they provide socialization opportunities for people with dementia and respite for their caregivers. While there is no known cure for dementia, there are ways in which slowing down the progression of the PWDs' conditions may be possible. For example, staying active and mentally engaged with continuous cognitive stimulation helps.

Most ADPs provide social and entertaining activities that meet the clients' specific needs and intervention plan in a physically and cognitively stimulating environment. They are beneficial for PWD through appropriate social and recreational activities like brain stimulating games and social engagements, which may slow down their conditions' deterioration and sustaining their mental and physical capacity. Such day services also provide family caregivers of PWD an opportunity to learn dementia-care related knowledge. For working caregivers, the ADPs made possible for them to leave their family PWD with the program and go to work or take a break from their caregiving obligations [16]. Meanwhile, ADPs facilitate the development of support groups and social networks for both PWD and their caregivers, which helps to reduce social isolation - they provide an inclusive, non-judgmental space to interact with others [17].

However, ADPs often have eligibility criteria set in place which includes age, types of behaviors (or lack thereof), independence, and certain types of dementia [16]. Aside from eligibility restrictions, there is often accessibility issue. Due to their difficulties in taking public transportation, they must depend on their family caregiver or others for attending ADPs. Moreover, accessibility does not only limit to physical access but information access, as many of these programs and services are not advertised well or easy to find.

Furthermore, ADPs would have out-of-pocket costs that are not covered by insurance or other benefit packages, which made them not affordable, especially to those with dementia and their families who often face heightened financial stress [18].

In Canada, there are ADPs access disparities among different groups [19]. Only when the service gaps can be identified and addressed, ADPs can reach their intended objectives and can effectively serve their clients.

\section{ADPs at the TGC}

The TGC's ADPs provide structured and supervised social, recreational, physical, and educational activities which aims to promote socialization, provides support and information services for clients living with dementia, post-stroke, frail seniors, and caregivers living in the community. Additionally, it offers congregate dining program to bring seniors together for nutritious meals, meet with others, and participate various activities.

Specifically, TGC's adult day services include the following:

\section{1) Adult Day Programs}

a) Special Day Program for PWD

b) Memory Training and Activity Centre for PWD

c) Adult Day Program with integrated care

d) Integrated care \& special care for dementia

2) Behavioral Support

3) Interventions for Dementia

a) Memory Training

b) Music \& Dance

c) Orientation Training

d) Reminiscence

e) Sensory Stimulation

4) Play Intervention for PWD

5) Assisted Living Services

6) Caregiver Education and Support Services

7) Community Health \& Education Centre (CHEC) Integrated care, special dementia care

These programs are designed to help those elders who are isolated from the community due to functional limitations, living with a cognitive impairment such as dementia, requiring assistance in daily living, and family caregivers who require regular periods of relief. 


\section{RESULTS}

\section{A. ADPs at the TGC are Helpful to Clients and Their Families}

The TGC's ADPs provide services to its target elder groups and their family caregivers, especially those who are caring for PWD; since studies found that the importance of social support and social participation in caregivers' mental health and wellbeing [20]. Family caregivers to PWD appreciate the services of the ADPs at the TGC that have met their needs of feeling belong and being supported, learned relevant skills, and enjoyed much needed breaks; and they found the programs are also effective for PWD. The following are the family caregiver participants' words:

"I spend $80 \%$ of my time at home, because my wife's brain condition degenerates, I have to take care of her. Every time after coming to participate in the day program activities, $I$ will be very happy. I know I am doing what I can and as much as I can. It broadened my perspective. At home, I do grocery shopping, take my wife to see her doctor, make breakfast and make dinner; and wake up at night to check if she's got her duvet on. She doesn't know, the duvet would often fall on the ground. For me, coming to (this day program) I learned how to better take care of my wife at home and how to take care of the elderly in general." - ADPs' client/family caregiver

"I found music therapy is quite good for them [dementia patients]. Some of them like pop music, some of them like opera. I got a music box from the Alzheimer's society. They downloaded some songs... I forced her to listen to the music at least 20 minutes a day." - ADPs client's daughter

"My husband was very good at bowling, football, and other sports. He did not like quiet activities. So now he likes to play mah-jongg. He is still quite skillful at Mah-jongg. And when the family accompany him to play mah-jongg, they purposefully make it more difficult for him in order to help him using his brain. His ability to play mah-jongg has not deteriorated at all." - ADPs client's wife

"My mother is doing fine. She joined the day program is just for being with others, really.” - ADPs client's son.

"He's now more outgoing. He praises me now. When I returning home from work, he would greet me and say, "oh you're home". He becomes quite tender. Also, he likes to groom himself more now. Before going to (the day program) in the morning, he would get up early and take a shower. I feel that the care he received here has changed him." - ADP client's daughter

While most of the client participants of this study have expressed their gratitude and appreciation to the ADPs, almost all staff participants found they can do more to improve the quality and the accessibility of the programs. It became apparent that if there was no resource constrains, the TGC's ADPs will be more effectively meet the needs of their clients.

\section{B. Accessibility is the Main Gap}

The participants of this study have identified language, program schedule, lack of supporting professional caregivers, and transportation inconvenience as existing gaps in the current program. All of them are about accessibility of the programs. Namely, language accessibility, physical accessibility, financial accessibility, and care accessibility.

1) Language Accessibility

In a multicultural society like Canada, language is an important element in eldercare facilities, as well as in ADPs. It determines potential clients' accessibility in a decisive way.

"Most seniors want to speak their own language, eat their own culture's food. Most of the seniors are well educated and can speak English, but they want to come here, to talk with others, and feel free to speak their mother tongue. A lot of (a language) speakers come to Canada, but not many come here. May be because the program supervisors here are speaking in (another language) when leading the activities." - An ADPs staff

"Running our day program is very hard, because some people in the program do not understand the language. The seniors would be very unhappy if the staff do not speak their language." - ADPs staff

"We speak [a language], the support group people cannot understand me. We went there once, but my husband couldn't understand what they have said. Then in the summer, a volunteer from a university came here and organized a support group that speak [the language of her husband's]. My husband went there and it was good." - A client's wife

"There is a lack of cultural-specific day programs. For example, among all the branches, only the branch I'm working at offers a day program that is in [a language], which means the clients who live in Richmond Hill would have to make a really long journey to come here. These are all obstacles that are preventing our target clients from attending our program." - ADPs staff

"Some of our staff members think we don't have many (a language) speaking elders join our adult day programs is due to the cost involved. I know it's simply a language issue. They can't understand (the programs' language), which is the language almost all of our programs use." - ADPs staff

"Some people at our Centre thought immigrant elders from certain areas do not like to enroll to our Adult Day Programs is due to the fees we charge. In reality, those elders won't benefit from our programs because they can't understand what we say." - ADPs staff

Language is certainly essential in a service program. The misperception of the target clients' disincentives and resource barriers made creating new programs for potential clients difficult.

\section{2) Physical Accessibility}

a) Programs' Schedule Issue

Staff members at the TGC found there are shortcomings of their current programs' schedule:

"Our programs' duration is 5 hours, and the program ends around $2 \mathrm{pm}$ or $3 \mathrm{pm}$, which is really awkward timing for caregivers who have jobs. So, the challenges for families to use our day programs are partly financial and partly due to the current day program schedule." - ADPs staff

"I have been advocating for a change of schedule for our day program. Now the day program starts at 10am, which means the caregivers have to drop them off around that time, which is awkward timing for caregivers who have a job. If their job starts at 9am, how can they drop off our clients around 10am? If the program has extended hours, then we 
can arrange different staff to go on different shifts. For example, ideally, some day programs open at 7:30 or 8:00am, so caregivers can drop off our clients before they go to work. If the day program closes at $7 \mathrm{pm}$, then after finishing work at 5pm, family caregivers can come here to pick them up". - ADPs staff

Part of the ADPs' function or support to family caregivers is to care for PWD during daytime, which would allow them to have breathing time. Good ADPs schedule would enable working age family caregivers to go to work and take less time off work [21].

\section{b) Transportation Issue}

Transportation is a problem area acknowledged by caregivers and the participants of ADPs alike. The main issues concerning transportation include long waiting time and long rout to the $\mathrm{TGC}$, since the driver must pick up several people from different locations. There is also a fee for the transportation service. Moreover, there is no assistance provided for the elders to get on and off the shuttle bus. However, elders not only need support for using the transportation, but many of them also need help for lock their doors when their family caregivers are not at home.

"One of the biggest barriers for them to access our service is transportation. Our transportation is just for within certain boundary. But our clients live in every location of the city. ...Because of their memory problem, they should always have someone to accompany them to our day programs." - ADPs staff

\section{3) Financial Accessibility}

ADPs' fees and transportation issue are access barriers to clients, pointed out by a few of the ADPs staff members, for example, one said:

"The Central program used to be free with transportation support, and it attracted lots of participants. Many seniors participated when the family detected an early onset of dementia, and it helped them maintaining a stable health condition. Our program measures our clients' health with two indicators - Mini-Mental State Examination (MMSE) and Geriatric Depression Scale (GDS). Our senior participants' scores used to be higher than the average scores of Ontario, but that's years ago. It is much harder for us to achieve these levels of scores now." - ADPs staff

This is an encouraging revelation that when access barriers were not there, the ADPs can help those in need in time and help them to maintain as good health condition as possible.

"Make the program free, so that people in need would be more willing to attend the day program. And also, offer them with free transportation to lessen the burden on caregivers." - ADPs staff

While most staff members with ADPs thought reduce or remove fees and provide free transportation can help more community elders, one staff member thought the program's fee is low and the cost-benefit effect is high:

"Our dementia day program costs $\$ 25$ a day. It is only the hourly rate for hire a caregiver at the hospital." - ADPs staff

\section{4) Care Accessibility}

High prevalence rate of dementia among clients requires professional caregivers. Over $50 \%$ of TGC's ADPs clients attending the adult day programs are PWD, and most of them are in later stages. However, the staff members managing the program are usually social workers who have no relevant caregiving skills. There is also no necessary equipment for assisting clients' movement.

"Those who ended up in our program are here because it is their last resort - their family simply cannot take care of them anymore. But such seniors do not get the full benefit of the program. The original plan of our day programs is to fill with activities that engage the seniors and offer positive stimulation to their brain. But now, due to the health condition of most participants, most of the program time is spent on personal care, like accompanying them to the washroom, giving them medicine, and walking them around. Some seniors need to go to the washroom 5 or 6 times during the day, and since they cannot walk with a walker, each time would need 2 staff to support the senior to walk to the washroom. This day program ends up being more like a daycare in a retirement home. If I were a trained social worker who were just hired for this program, I would want to design art or music activities to engage the seniors and make their day enjoyable, but in reality, I spend most of the day helping them go to the washroom. This is challenging for our staff." - ADPs staff

"During the later stages of dementia, some seniors would lose the ability to use the toilet independently. For example, when a senior goes to the toilet, they have completely forgotten the whole procedure. That's when the family feels they should send the senior to our program. Such seniors would immediately create a huge workload for us once they're sent to our program. If a senior needs two-person transfer, then they are actually no longer suitable for our day program. That type of care level is offered by the long-term care unit. Our program has a different staff-client ratio. However, when many dementia patients are sent to our program, their conditions are already quite serious. Our challenge is, while we try to maintain this service unit, the seniors that our unit is prepared to serve, who are in relatively good conditions, do not get sent to us by their family. Those who come to attend our program are mostly already in the later stages of dementia, whose conditions are more serious than what we can handle." - ADPs staff

"There are several aspects of challenge: there is a lack of support. There are many - more and more elderly clients need more help, some of them are using wheelchairs. If you need to help them for going to the bathroom, there is no equipment. No personal support for these seniors is a big challenge. There are many elders with dementia in the mixed groups." - ADPs staff

It is evident that professional caregivers are very much needed in these ADPs.

\section{DISCUSSION}

The TGC's ADPs have received effective results. Service users reported music and emotional support programs very helpful. Some praised the meals provided by the TGC as they met their appetite preferences, and some have found new friends and/or new knowledge.

ADPs clients who are family caregivers to PWD and the ADPs' staff expressed their views based on their lived 
experiences. These are invaluable for the ADPs' future development.

\section{A. Tackle the Issue of Mismatch between ADPs and Their Clients' Needs}

The ADPs staff members at the TGC have been making efforts to improve the quality of lives of their elder clients. They hope the intervention programs could reach out to those at the early stage of dementia, since early enrolment is key for PWD and their family caregivers, who would experience social isolation due to difficulty managing symptoms, and fear of stigma and embarrassment, and various other reasons [19]. Based on the participants of this study, diagnose also takes time.

"Our day programs have materials like admission package, workshop, booklet, and courses. Our programs include three main categories: 1. knowledge, like knowledge about diseases such as diabetes and dementia; 2. skills, like caregiving skills; and 3. wellness, improve their ability to take care of themselves. For support groups, we guide them with different needs. It's hard to take care of those elders with dementia, because we only have one and a half social workers in a program: one program worker and one leader. The age range we serve is 75-97 years. " - ADPs staff

"For clients at early stages of dementia, being in the social activities at our program gives their brains good stimulation exercises". - ADPs staff

"If they are sent to the Adult Day Programs early, it will help to keep them in a relatively good condition and maintain their quality of life." - ADPs staff

Thus, different kinds of ADPs are needed to tailor to address differing needs. Implementing mechanisms to identify the needs of their potential clients and families, and providing access to appropriate care providers and programs could strengthen the ability of ADPs to improve the experience and health outcomes of the elderly clients and families they serve. ADPs have the potential to help shape healthcare system interventions, indeed [22].

\section{B. Limited Staff vs. High Rate of Dementia Prevalence Reduces the Quality of Services Provided}

A high percentage of clients who have joined the TGC's ADPs are PWD. This makes providing eldercare more challenging for both staff and family caregivers. The mismatch between the clients and the programs has been a big challenge. Since most of the clients joined the programs are already in the later stages of dementia, the intended goals of the programs could not be met; and persons with later stages of dementia cannot benefit from the programs as the programs were designed for. Just like some staff members said:

"Those who do ended up in our program here because it is their last resort - their family simply cannot take care of them anymore. But such clients do not get the full benefit of the program." - ADPs staff

"There are about 50\% of participants to our Adult Day Program are persons with dementia." - ADPs staff

"We are mostly busy with babysitting the elders instead of running the program now." - ADPs staff

"Most of us who are managing the day programs have social work training background. We are not equipment with providing care for the elders." - ADPs staff
"If I were a trained social worker who were just hired for this program, I would want to design art or music activities to engage the seniors and make their day enjoyable, but in reality, I spend most of the day helping them go to the washroom." - ADPs staff

ADPs are playing an important role in supporting community elders' various needs. At the time when there are barriers in accessing long term care homes, such a program is particularly crucial. The day programs at the TGC supported needed elders with socializing, caregiver support, and dementia care. However, due to financial constraints, the ADPs was unable to optimize its service scale and quality for meet the needs of its clients. Thoughtful staff members of ADPs at the TGC have thought about the potential changes in detail. Facing the reality, they know that ADPs must make necessary changes in order to truly help those with early stages of dementia.

\section{CONCLUSIONS AND RECOMMENDATIONS}

Community supporting services to elders like the TGC's day programs are essential. They have contributed to the quality of lives of elders in need and their respective families. However, these programs face financial constrains that limiting their capacity. They can be more effective in assisted local community elders in need if more resources are available, such as required number of staff and necessary equipment and devises. More staff members onsite, especially professional caregivers, can meet the needs of those persons with dementia or other disability who access ADPs services. Increased availability of new technologies may improve services and caregivers' working conditions. For example, brain stimulation devices can help to prevent dementia or slow its progression, make dementia patient lives more interesting, and reduce patient dependence on family for conversation; fall prevention devices can detect lower limb weakness and barriers; and there will also likely be devices available for assisting caregivers in lifting heavy objects, etc., to reduce the risk of injury and other bodily harm of the elders and caregivers alike.

The ADPs staff members at the TGC are invaluable assets of the institution. They are not only caring, but also thoughtful, including contributing their time and energy on envisioning an improved version of its ADPs. Their recommendations on the improvement of ADPs at the TCG include providing (1) a comfortable and accommodating environment; (2) emotional, cultural, and social comfort and familiarity to seniors; (3) a flexible service scheduling and meeting seniors' needs, and (4) support for staff and caregivers.

1. Comfortable and accommodating environment

- A bigger space and a walking trail that allow the clients to walk around and feel less restrained when attending activities

- A resting area for the clients who would like to take a break from a scheduled activity

- A designated dining area for the clients to have an appropriate place to have meals right after completing their programs. 
- A comfortable lounge area for socializing, which can serve for multipurpose use by both the clients and caregivers

- A quiet environment with a good sound system

- A caring environment that supports and encourages socialization and mutual support

- Create language specific programs or centres

2. Emotional, cultural, social comfort, and familiarity

- Relevant wall decoration that makes the clients feel home

- Staff of the programs with a passion in serving seniors and willing to get to know their clients; ideally, staff shall have multi-talents such as can play musical instruments and/or singing

3. Improved services

- Have a mix of structured programs and programs of the clients' choice that can engage the clients, and a variety of activities

- Design a flexible program schedule (for example, from $7 \mathrm{am}$ to $7 \mathrm{pm}$ ) for the convenience of family caregivers who have day jobs

- Provide properly equipped instruments with assistive devices such as easy listener, walker, and wheelchair

- Install an onsite nurse, and physiotherapist or occupation therapist

- Provide nail cutting service onsite and make it available multiple days a week

- Provide regular physical checkup for the clients

- Assisted bathing services

- Fees can be minor to free of charge for the clients with financial difficulties

- Free transportation services for all clients

4. Support for staff and caregivers

- A team of staff that can help, support, and motivate each other

- A support group for family caregivers of ADPs clients, especially PWDs, to meet-and-greet once a week or so

- Train and hire "personal support worker assistants" who can provide services that are heavily relying on family caregivers now. It will be a job with short training, but can lift the burden from the families, while improving quality of care

\section{ETHICS APPROVAL}

This study received the University of Waterloo's ethics review clearance (\#22276).

\section{ACKNOWLEDGMENT}

Staff members of the TGC provided field access and other support generously. All participants of the project contributed their rich experience, insight, and knowledge. Lily $\mathrm{Wu}$ transcribed interviews and focus group discussions data; Adam Mursal, Ivy Li, and Lily Wu offered their assistances in fieldwork data collection process. This project received funding from the SSHRC Institutional Grant of the University of Waterloo. The author is grateful to all who have made tangible and intangible contributions to the project.

\section{CONFLICT OF INTEREST}

Authors declare that they do not have any conflict of interest.

\section{REFERENCES}

[1] Statistics Canada. Canada's population estimates: Age and sex. [Internet] [cited 2019 July 1] Available from: https://www150.statcan.gc.ca/n1/daily-quotidien/190930/dq190930aeng.htm

[2] Grant and Agius. Census 2016: The growing age gap, gender ratios and other key takeaways 2017. [Internet] Available from: https://www.theglobeandmail.com/news/national/census-2016statscan/article34882462/

[3] Government of Canada - Action for Seniors report, 2014. [Internet] Available from: https://www.canada.ca/en/employment-socialdevelopment/programs/seniors-action-report.html

[4] Runac RE. Dementia Care: Effects of Care Load and Couple Age on Perceptions of Abuse, Abuser, and Abused MS, Thesis, University of Alberta; 2020.

[5] Chapman DP, Williams SM, Strine TW, Anda RF, Moore MJ. Dementia and its implications for public health. Prev Chronic Dis. 2006; 3(2): A34.

[6] Chambers LW, Bancej C, McDowell I. (Eds) Prevalence and Monetary Costs of Dementia in Canada. The Alzheimer Society of Canada in collaboration with the Public Health Agency of Canada. Toronto, Ontario, Canada. 2016.

[7] Silvaggi F, Leonardi M, Tiraboschi P, Muscio C, Toppo C, Raggi A. Keeping People with Dementia or Mild Cognitive Impairment in Employment: A Literature Review on Its Determinants. Int. J. Environ. Res. Public Health. 2020; 17: 842.

[8] Alzheimer Society of Canada (n.d.). "What is Dementia” [Internet] [cited 2021 October 18] https://alzheimer.ca/en/about-dementia/whatdementia

[9] Hugo J, Ganguli M. Dementia and Cognitive Impairment: Epidemiology, Diagnosis, and Treatment. Clinics in Geriatric Medicine. 2014; 30(3): 421-422.

[10] Jefferies K, Agrawal N. Early-onset dementia. Advances in Psychiatric Treatment, 2009; 15: 380-388.

[11] Hsu et al. Understanding the impact of COVID-19 on residents of Canada's long-term care homes - ongoing challenges and policy responses, International Long-Term Care Policy Network, 2020

[12] Canadian Institute for Health Information (CIHI, 2016). "Home Care Reporting System, 2015-2016" [Internet] [cited 2021 October 18] https://www.cihi.ca/en/home-care-reporting-system-metadata

[13] Canadian Institute of Health Research (CIHR, 2018) "Dementia in Canada" [Internet] [cited 2021 July 4] Available from: https://www.cihi.ca/en/dementia-in-canada

[14] Vanier Institute. "Snapshot”[Internet] 2017 [cited 2019 November 30] Available from: https://vanierinstitute.ca/snapshot-family-caregivingwork-canada/

[15] Dong W. Informal Caregiving and Its Hidden Cost to National Economy: With a Toronto Case Study. EJ-MED 2022; Volume-4, Issue-1. Pp15-23

[16] Shnall A, Agate A, Grinberg A, Huijbregts M, Nguyen MQ, Chow TW. Development of supportive services for frontotemporal dementias through community engagement. Int Rev Psy-Chiatry. 2013; 25(2): 246-252.

[17] Bangerter LR, Liu Y, Kim K, Zarit SH. Adult Day services and dementia caregivers' daily affect: the role of distress response to behavioral and psychological symptoms of dementia. Aging \& Mental Health, 2021; 25:46-52,

[18] Sansoni J, Duncan C, Grootemaat P, Capell J, Samsa P, Westera A. Younger Onset Dementia: A Review of the Literature to Inform Service Development. American Journal of Alzheimer's Disease \& Other Dementias, 2016; 31(8): 693-705.

[19] Tam-Tham H, Nettel-Aguirre A, Silvius J, Dalziel W, Garcia L, Molnar $\mathrm{F}$, et al. Provision of dementia-related services in Canada: a comparative study. BMC Health Services Research. 2016; 16: 184.

[20] Sibalija J, Savundranayagam MY, Orange JB, Kloseck M. Social support, social participation, \& depression among caregivers and noncaregivers in Canada: A population health perspective. Aging \& Mental Health. 2020; 24(5): 765-773.

[21] Dong, W. "Dementia Care Study Feedbacks" at the Innovative Practices in Dementia Care Symposium, Toronto, Ontario. March 26. 2019. 
[22] Ellen ME, Demaio P, Lange A, Wilson MG. Adult Day Center Programs and Their Associated Outcomes on Clients, Caregivers, and the Health System: A Scoping Review. Gerontologist, 2017; 57(6): 8594.

[23] Statistics Canada. Research Highlights on Health and Aging [Internet] $2016 . \quad$ https://www150.statcan.gc.ca/n1/pub/11-631-x/11-631x2016001-eng.htm

[24] Statistics Canada. "Canada's population estimates: Age and sex, July 1, 2019” [Internet] 2020. https://www150.statcan.gc.ca/n1/dailyquotidien/190930/dq190930a-eng.htm

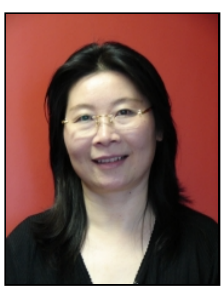

W. Dong is a social sciences scholar affiliated with the University of Waterloo. She received her $\mathrm{PhD}$ degree from the Department of Sociology and the Comparative Program on Health \& Society of the University of Toronto, and her postdoctoral training was with the Canadian Institute of Health Research (CIHR) as its Rudolf Virchow Memorial Postdoctoral Fellow. She has served as Senior Fellow at the Munk School of Global Affairs of the University of Toronto, and as a Visiting Professor at international settings.

Her area of study is social policy, which includes healthcare and pension. Her main area of study is the wellbeing of vulnerable population groups, such as the poor, elders, and migrants. Her recent studies include elders' collective dwelling community and elders' quality of life in Canada. Professor Dong teaches courses such as social policy, comparative healthcare systems, and research design. Her publications include edited books Social Policy in China: From State-led to Marketled Economy (2019) and Public Health Sciences (2009), and dozens of journal articles. 